\title{
Audible Noise Levels of Oxygen Masks Operating on Venturi Principle
}

\author{
JULIAN M. LEIGH
}

British Medical fournal, 1973, 4, 652

\section{Summary}

Certain oxygen therapy masks operating with a venturi were found to possess audible noise levels sufficient to cause annoyance to the user. This was not true of all masks. However, it is recommended that this is a source of noise pollution that should be eliminated by the manufacturers of such devices.

\section{Introduction}

In the field of oxygen therapy accuracy in dosage is achieved by devices which operate with a venturi. In these devices a jet of oxygen entrains air in a fixed proportion so that flows of between $33 \mathrm{l} . / \mathrm{min}$ (40\% masks) and $96 \mathrm{1} . / \mathrm{min}(24 \%$ masks) are available for the patient.

It was observed that different versions of these devices differed in their audible noise levels, and that in some cases this could be irritating to the user. Consequently, measurements were made to compare the audible noise levels of some of these devices.

\section{Materials and Methods}

Three types of mask which vary in design but not in the principle of their operation were examined. The Hudson Multivent is a device in which air entrainment ratio can be varied by adding a series of separate "restrictor discs" to produce 24,28 , 35 , and $40 \%$ oxygen. To obtain the same concentrations Vickers produce a series of separate Ventimasks, and the O.E.M. Company make a similar series of Mixomasks. Tests were carried out which included the range of concentrations of both Ventimasks and Multivents and a $28 \%$ Mixomask.

Measurements were made in a soundproof room. Each mask was clamped into a retort stand so that the site of the venturi was $10 \mathrm{~cm}$ away from a condenser microphone (Brüel and Kjaer, 4111), and connected in turn to a spectrum analyser (Brüel and Kjaer, 2109). Noise levels were read from the meter and display was achieved on a Tektronix $5103 \mathrm{~N}$ storage oscilloscope. Illustrations (time base- $1 \mathrm{msec}$ per large square) were made with a Tektronix C27 polaroid camera. Before each measurement was made the background noise level was measured. This noise consisted entirely of that produced by the oxygen flowmeter.

\section{Results}

The results, expressed as noise level ( $\mathrm{db}$ ) above background, are given in the table.

Since $1 \mathrm{db}$ is $10 \log _{10}$ of the power ratio being compared $+3 \mathrm{db}$ is equivalent to doubling the noise power level and $-3 \mathrm{db}$ to halving the noise power level. On examination of the results it

Magill Department of Anaesthetics, Westminster Hospital, London SW1P 2AP

JULIAN M. LEIGH, M.B., F.F.A. R.c.s., Senior Lecturer and Honorary Consultant
Results of Tests expressed as Noise Level (db) Above Background

\begin{tabular}{|c|c|c|c|c|c|c|c|c|}
\hline & & & & & \multicolumn{4}{|c|}{ db Above Background } \\
\hline & \multicolumn{4}{|c|}{ Oxygen concentration: } & $24 \%$ & $28 \%$ & $35 \%$ & $40 \%$ \\
\hline $\begin{array}{l}\text { Multivent } \\
\text { Mixomask } \\
\text { Ventimask }\end{array}$ & $\begin{array}{l}. \\
\cdots\end{array}$ & $\begin{array}{l}\ldots \\
\cdots\end{array}$ & $\begin{array}{l}. \\
\ldots\end{array}$ & $\begin{array}{l}. \\
\therefore\end{array}$ & $\frac{45}{27}$ & $\begin{array}{r}39 \\
30 \\
6\end{array}$ & $\frac{33}{8 \cdot 5}$ & $\frac{35}{11}$ \\
\hline
\end{tabular}

can be seen that the quietest mask was the $28 \%$ Ventimask, having a noise power level four times that of the background. Not surprisingly the $24 \%$ masks were the noisiest since they produce a total flow of $96 \mathrm{l} . / \mathrm{min}$. The noisest mask of those tested was the $24 \%$ Multivent with a noise power level $2^{15}$ times that of the background. The Multivent masks were always noisier than the equivalent Ventimasks - the smallest difference being in the $24 \%$ masks ( $2^{6}$ - that is, 64 times the power). The largest difference was in the $28 \%$ masks, the Multivent having $2^{11}(2,048)$ times the noise power level of the $28 \%$ Ventimask.

The $28 \%$ Mixomask was $9 \mathrm{db}$ down on the $28 \%$ Multiventthat is, one-eighth of the noise power level-but still $24 \mathrm{db}$ up ( $2^{8}$ or 256 times the power) on the $28 \%$ Ventimask.

\section{Discussion}

It is clear that the variation in design of these different devices affects the amount of turbulent gas flow produced within them and consequently the variations in audible noise levels.

The irritation caused by noise is affected not only by the power level but also by the distribution of frequencies. If the frequency band is small then noise levels of equivalent power are more irritating. The continuous hissing noise of these devices has a maximum frequency content of roughly 500$3,500 \mathrm{~Hz}$ (the range of audible frequencies in man is about 26$18,000 \mathrm{~Hz}$ ).

So far as power levels are concerned, the noise of rustling leaves is about $8 \mathrm{db}$, background noise in the average home is about 20-30 db, and of a motor car about 40-50 db (Freeman and Morgan, 1967), while the limit of acceptable traffic noise has been recommended to be not greater than $70 \mathrm{db}$ for $10 \%$ of the time (Motoring Which?, 1973).

This study showed that some of the devices produced noise levels which varied between that produced by rustling leaves and that which may be heard in the average home, while others encroached to within the range of noise produced by a motor car. Bearing in mind that the hiss has a small frequency band and the fact that the noise has to be listened to by the user for $100 \%$ of the time, the irritating quality is relatively increased.

These types of oxygen masks are disposable, and since sales are in excess of one million per annum, and likely to increase, it is an attractive area for manufacturers. In the current era of a society conscious of noise pollution it is clear that those who already, or may in the future, manufacturer this type of device should attend to this point lest they subject ill patients to unnecessary irritation.

I acknowledge the help of Mr. D. A. P. Strickland and Mr. R. Robbins of the Department of Clinical Measurement, Westminster Hospital.

\section{References}

Freeman, Ira, M., and Morgan, W. (1967). Physics Made Simple. London, Motoring Which? (1973). April issue. London, Consumers' Association. 